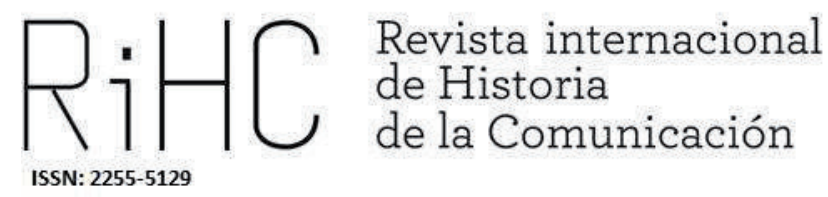

\title{
LA TRADUCCIÓN COMO PROBLEMA EN LA PRENSA VIRREINAL. EL CASO DEL SEMANARIO DE AGRICULTURA, INDUSTRIA Y COMERCIO (1802-1807)
}

Translation as a problem in the viceregal press. The case of the Semanario de Agricultura, Industria y Comercio (1802-1807)

DOI: http://dx.doi.org/10.12795/RiCH.2021.i16.13

Recibido: $18-12-2020$

Aceptado: 25-5-2021

Publicado: 30-6-2021

Dr. Matías Maggio-Ramírez

Universidad Nacional de Tres de Febrero (UNTREF), Argentina mmramirez@untref.edu.ar

ORCID (ID) 0000-0002-1106-1381 
Resumen: El análisis de las fuentes de información del Semanario de Agricultura, Industria y Comercio, que se publicó en Buenos Aires entre 1802 y 1807, permitió cuestionar la historiografía tradicional que le atribuyó a Juan Hipólito Vieytes, editor del periódico, el rol de traductor. El análisis comparativo de las fuentes demostró que las traducciones francesas que se reprodujeron en el periódico no se realizaron en Buenos Aires, sino que tenía como origen Madrid. La atribución de las traducciones puso en valor a los periódicos españoles de finales del siglo XVIII y principios del siglo XIX, para los lectores americanos, y permitió relacionar la prensa virreinal bonaerense con la práctica de lectura de los libros de lugares comunes.

Palabras clave: Autoría; Traducción; Bibliotecas; Semanario de Agricultura, Industria y Comercio; Juan Hipólito Vieytes; Circulación de la información; prensa virreinal.

Abstract: The analysis of the sources of information of the Semanario de Agricultura, Industria y Comercio, which was published in Buenos Aires between 1802 and 1807, made it possible to question the traditional historiography that attributed to Juan Hipólito Vieytes, editor of the newspaper, the role of translator. The comparative analysis of the sources showed that the French translations reproduced in the newspaper were not made in Buenos Aires, but originated in Madrid. The attribution of the translations gave value to the Spanish newspapers of the late eighteenth and early nineteenth centuries, for American readers, and made it possible to relate the Buenos Aires viceregal press to the practice of reading commonplace books.

Keywords: Authorship; Translation; Libraries; Semanario de Agricultura, Industria y Comercio; Juan Hipólito Vieytes; Information Circulation; Viceroyalty Press.

\section{La atribución como problema}

El objetivo de revisar la bibliografía que abordó la historia de la prensa virreinal porteña sólo tiene sentido si también se cuestionan los pilares que sostuvieron esas investigaciones. Al analizar las fuentes en las que abrevó Juan Hipólito Vieytes, editor del Semanario de Agricultura, Industria y Comercio -entre 1802 y 1807-, para dotar de contenido frecuente a su periódico, se hallaron distintas estrategias para la gestión de la información. El editor ofició de mediador entre culturas al incorporar en su impreso traducciones de periódicos europeos, junto con las colaboraciones de autores americanos que se escondían bajo seudónimos anagramáticos. Desde el "Prospecto", Vieytes se atribuyó las traducciones, aunque de forma implícita. El trabajo que sigue buscó analizar la circulación de la información, realizar las atribuciones de las traducciones y comenzar a indagar en las máscaras de la autoría durante el período virreinal. En síntesis, se intenta indagar si la prensa de Buenos Aires fue un centro de 
traducción de la ilustración francesa a principios del siglo XIX, o si por el contrario fue heredera de la ilustración católica española ${ }^{1}$.

La bibliografía que abordó el Semanario intuyó que las piezas publicadas de forma anónima y aquellas que remitían a la traducción de un periódico extranjero, fueron realizadas por el editor. Esto último tal vez se infería porque Vieytes contaba en su nutrida biblioteca con diccionarios en inglés, francés-inglés, italiano-francés, españolinglés y español-francés. Desde el "Prospecto" el publicista se instalaba como el mediador de contenidos europeos en América, y tal vez esa postura fue la que sustentó la hipótesis de Vieytes como traductor que se sostuvo desde finales del siglo XIX (Gutiérrez, 1866; Zinny, 1869; Weinberg, 1956; Torre Revello, 1956; Maggio-Ramírez, 2008; Martínez Gramuglia, 2009; Rojas, 2010; Díaz, 2012).

El inventario de la biblioteca de Vieytes se realizó en 1815 , pocos meses antes de su muerte. El escribano Narciso de Iranzuaga y el bibliotecario primero de la Biblioteca Pública de Buenos Aires, Luis José de Chorroarín, declararon que hallaron entre los periódicos encuadernados: L'esprit des journalistes de Trévoux en 4 volúmenes, el Espíritu de los mejores diarios en 12 volúmenes y el Semanario de Agricultura y Artes dirigido a los párrocos con 14 volúmenes (Torre Revello, 1956). Las fuentes francesas que aparecían citadas en el Semanario de Agricultura porteño no se encontraron en la biblioteca del publicista.

Los estudios sobre la prensa y la cultura virreinal, desde Juan María Guitérrez (1866) y Antonio Zinny (1869) en adelante, atribuyeron los textos sin firma en los periódicos virreinales porteños usualmente a sus editores, Francisco Cabello y Mesa del Telégrafo Mercantil, Rural, Político, Económico e Historiográfico del Río de la Plata (1801-1802), Juan Hipólito Vieytes del Semanario de Agricultura, Industria y Comercio (1802-1807) y Manuel Belgrano del Correo de Comercio (1810-1811). Los trabajos que rastrearon las lecturas y apropiaciones de textos españoles en la prensa porteña se focalizaron en los usos del Correo Mercantil en el Telégrafo Mercantil (Martini, 1998), las transcripciones de las cartas Valentín de Foronda del Espiritu de los mejores diarios en el Semanario de Vieytes (Fernández López, 2005) y la transcripción de los artículos de François Véron Duverger de Forbonnais en el Correo de Comercio, que se habían publicado por primera vez en la Enciclopedia de Diderot y luego fueron traducidos al castellano por Carlos Lemaur (Maggio-Ramírez, 2020). Por lo que queda todavía un espacio vacante para

\footnotetext{
${ }^{1}$ El amalgama de la cultura eclesiástica y laica durante el virreinato del Río de la Plata permitió a José Charlos Chiaramonte (2007) unir dos términos que parecían contradictorios para dar cuenta de cómo las ideas ilustradas fueron apropiadas por los eruditos que se habían formado en el ámbito de los colegios jesuíticos. La ilustración católica y la cultura ilustrada fueron conceptos de Chiaramonte que se retomaron en el análisis de la prensa virreinal de Nueva Granada por Renán Silva (2005).
} 
reponer las fuentes en las que abrevó el Semanario de Vieytes y analizar el origen de las traducciones.

Para rastrear las fuentes de información se decidió comparar los artículos publicados en el Semanario porteño con aquellos periódicos que sí estuvieron en la biblioteca de Vieytes. Los artículos publicados sin mención autoral y con pie de cita de un periódico francés o inglés, fueron comparados con los impresos digitalizados en la Hemeroteca Digital de la Biblioteca Nacional de España; para realizar así la correcta atribución del origen de esos textos.

\section{La prensa española durante la llustración}

El siglo XVIII estuvo marcado por el auge de la prensa periódica y la divulgación del conocimiento. Desde 1797 hasta 1808 el Semanario de Agricultura y Artes dirigido a los párrocos fue uno de los periódicos españoles leídos en América, tanto de forma directa como indirecta. El espectro temático de la publicación, además de los tópicos de su título, incluyó cuestiones de economía política y crítica de costumbres; a la vez que apeló al clero ilustrado para fomentar la mediación entre la cultura escrita y la oral².

Los periódicos dieciochescos se insertaron en la tradición de los impresos en papel de baja calidad, en pequeños formatos y publicados con letra apretada con escasas ilustraciones (Urzainqui, 2003). La prensa en la segunda mitad del XVIII, además de abordar temas literarios, se interesó por la crítica institucional y de costumbres; así como por temas económicos. Esos papeles estaban acorde al espíritu crítico dieciochesco que contraponía al noble ocioso y al pobre trabajador como lugar común literario. También se denunciaban las diferencias sociales y sugerían los medios para cambiar el presente (Sáinz, 1983).

\footnotetext{
${ }^{2}$ Se recomienda aquí seguir los pasos de Elisabel Larriba en sus investigaciones centradas en el Semanario de Agricultura y Artes que desde distintas artistas marcó un modelo a seguir para el estudio de la prensa dieciochesca. Por ejemplo, abordó la materialidad del impreso, al indicar que cada seis meses los números publicados eran encuadernados y puestos a la venta en forma de códice (Larriba y Dufour, 1997: 26), así como el recorte temático, en las distintas gestiones del impreso, en función de las ideas económicas propuestas por Manuel Godoy. También se interesó en la representación de las instancias de lectura, por ejemplo al indagar el uso de las imágenes con fines instruccionales (Larriba, 2005), rastrear a los lectoressuscriptores (Larriba, 2013) y en reponer cómo pasó de ser un periódico pensado para el público a una publicación hecho para y por especialistas (Larriba, 2014). De alguna manera siguió la propuesta analítica de Roger Chartier (1994) que aconsejaba analizar las tensiones entre los textos, los impresos y la instancia de lectura.
} 
La modernidad que declamaban los impresos económicos, en tanto signo de novedad que se oponía a lo antiguo, se cifraba en los conocimientos utilitarios que eran instrumentales para intervenir en el presente y así fomentar, desde el paradigma fisiócrata, la industrialización de la agricultura para su ingreso al comercio. La periodicidad semanal o bisemanal de los periódicos implicaba una rápida gestión y producción del contenido, por lo que el editor no se encontraba solo en la tarea. Las páginas estaban abiertas a literatos, que contaban con cierto grado de afinidad, a los lectores, que querían ver su nombre en letras de molde, pero también se daban a conocer textos tomados de otros periódicos.

El diálogo, propio del espíritu ilustrado, también era el espacio para polémicas, controversias y múltiples puntos de vista que tenían en la prensa una plataforma que visibilizaba la voz del escritor periódico. La palabra impresa de los papeles públicos no se centraba en la individualidad de la autoría ni en la originalidad de la obra sino en exponer ideas (Sánchez-Blasco, 2013: 25). Es decir, a diferencia del escritor literario que intentaba vivir de su prosa y que cuestionaba a los plagiarios; el periodista no tenía conciencia de la propiedad de la palabra porque apelaba al interés común en favor del progreso de la comunidad. La utilidad de los textos estaba por encima del reconocimiento de la autoría, que como sostuvo Sánchez-Blasco, el literato dieciochesco -a diferencia del humanista- copia, sintetiza y traduce porque "sustituye en gran medida la creación o la investigación individual" (2013: 28).

Se multiplicaron las traducciones en la prensa tanto del francés, del inglés, el italiano y hasta del alemán; que nutrieron emprendimientos literarios como el Espíritu de los mejores diarios literarios que se publican en Europa, y el Semanario de Agricultura y Artes dirigido a los párrocos, que fueron leídos en Buenos Aires.

\section{La prensa porteña}

En los "Análisis" y "Prospectos" americanos, que se publicaban antes que saliera el primer número de un periódico como estrategia para captar suscriptores, se hacía hincapié en que los contenidos estarían al tono de lo que se leía en Europa. Los lectores, y suscriptores, intervinieron en la prensa tanto con sus nombres como con seudónimos, grecismo y anagramas. Francisco Antonio Cabello y Mesa, editor del Telégrafo Mercantil, Rural, Político, Económico e Historiográfico del Río de la Plata (TM), que se publicó entre 1801 y 1802, utilizó el imperfecto anagrama Narciso Fellobio Canton, así como los seudónimos El Telegrafista y el Filósofo indiferente principalmente para varios artículos de críticas de costumbres. El Doctor don Domingo de Azcuénaga y Basavilbaso firmó con sus iniciales D.D.D.A., José Joaquín de Araujo fue El Patricio de Buenos Aires, el deán Gregorio Funes firmó como Patricio Salliano, Eugenio del Portillo utilizó el 
seudónimo anagramático Enio Tullio Grope, Cristobal Martín de Montúfar firmó como C.M.M., Pedro Juan Fernández y Almada fue el Infausto Pastor, el doctor Cosme Argerich firmaba como D.C.A y doña María Antonia del Río Arnedo firmó como La amante de su patria (Martini, 1998).

Vieytes en su Semanario firmó textos como Julián Topio, anagrama de Juan Ipólito, y como "Su apasionado H." (Fernández López, 2005). Manuel José de Lavardén, el poeta que supo publicar la "Oda al Paraná" en el primer número del Telégrafo Mercantil utilizó en el Semanario un seudónimo anagramático -Juan Anselmo de Velarde- en las tres cartas que publicó y que unos años más adelante se reprodujeron en el periódico madrileño Regañón General (Maggio-Ramírez, 2020a). También se habilitaba la recepción de textos de plumas locales, con distintas restricciones de acuerdo al periódico. Por ejemplo, el Telégrafo Mercantil recalcó el laconismo como propio del género periodístico (TM, 27/5/1801), y el Semanario en el género literario, por ejemplo al rechazar un poema sobre la araña (Correa Luna, 1928). Los lectores de la prensa bonaerense, en el virreinato del Río de la Plata, que enviaron sus textos a los editores usaron las mismas estrategias que tiempo atrás se habían llevado adelante con maestría en los periódicos americanos como la Gazeta de literatura de México (Valdez Garza, 2014) y el Mercurio Peruano de Lima (Clément, 1997).

Los temas que se anunciaron en el "Prospecto" de los impresos funcionaron como un horizonte de expectativas sobre los contenidos futuros, a la vez que enmarcaba la publicación en los límites de la censura virreinal y ahondaba sobre cada una de las palabras del nombre del periódico. La producción y gestión de los textos, que respondían a los múltiples temas anunciados, era una meta a cumplir que semana a semana se renovaba para el editor. Sostener a principios del siglo XIX la periodicidad, con una imprenta manual, implicaba contemplar los tiempos de los componedores, la impresión propiamente dicha, la circulación del periódico y el cobro de la suscripción ya que muchos porteños se escondían del cobrador- a pesar de recibir el impreso (TM, 29/08/1802).

La brevedad, el costo reducido de la suscripción, la actualidad y la variedad de temas que se abordaban en la prensa, eran ventajas comparativas en relación al libro (Goldgel, 2013). La prensa anterior a 1807, fecha de la segunda invasión inglesa a Buenos Aires, tuvo como ejes temáticos la crítica de costumbres, la economía política y el fomento de diferentes géneros literarios. En los confines del imperio borbónico la prensa porteña fue heredera del libro de lugares comunes, del commonplace book, ya que compiló fragmentos del saber tanto de la Enciclopedia de Diderot y D'Alambert, de la Historia Natural de Buffon como del Diccionario de Agricultura del abate Rozier pero también de los periódicos que se publicaron en España. 


\subsection{El Semanario de Vieytes}

El Semanario de Agricultura, Industria y Comercio apareció el 1ㅇ de septiembre de 1802 hasta el 25 de junio de 1806 frente a la primera invasión inglesa a Buenos Aires. El periódico volvió a publicarse entre el 24 de septiembre del mismo año hasta el 11 de febrero de 1807, ante la inminencia de la segunda invasión inglesa. La publicación se reanudó gracias a los oficios del virrey Santiago de Liniers, que recuperó las palabras de Diego de Saavedra y Fajardo al referirse a la imprenta como el medio para propagar "con mayor prontitud las disposiciones y ordenes concernientes al mejor gobierno, e ilustración de los pueblos" (SAIC, 24/9/1806). La prensa siguió con la publicación seriada de los diálogos entre Feliciano y Cecilia para la educación de los niños, que era propio del Semanario español, pero el acontecimiento en tiempo presente ocupó las páginas más allá de las entradas y salidas de navíos de los puertos de Buenos Aires o Montevideo. La novedad como acontecimiento temporal reciente irrumpió en la prensa. El temor a la segunda invasión inglesa de 1807 habilitó la publicación de noticias, que se transcribieron de periódicos europeos, para comprender las derivas de la política europea.

Vieytes centró su publicación en los temas advertidos en el título y en cuestiones ligadas a la salud y educación pública. En el "Prospecto" del Semanario se buscaba fomentar la agricultura, con métodos modernos e ilustrados, para mejorar su rendimiento y así lograr que los labradores tuvieran excedentes en su producción por encima de su nivel de subsistencia. Enmarcado en los principios de la economía política dieciochesca se fomentaba la producción para que el sobrante pudiera incorporarse al mercado para su manufactura. De ahí la palabra "industria", que se encuentra en el título del Semanario, para que el producto agropecuario, transformado artesanalmente, entrara en el comercio. La importancia de la prensa por la prédica en favor del cambio de las costumbres, en la búsqueda del fomento del lujo de comodidad, en vez del lujo de ostentanción como sostuvo el napolitano Antonio Genovesi, cuyas lecciones circularon por Buenos Aires (Díez Rodríguez, 2001; Fernández Armesto, 2005). Se esperaba quebrar la transmisión generacional del saber para que la razón ilustrada de la "sabia Europa", al decir de Vieytes, llegara a la campaña bonaerense. Los mediadores propuestos, en las escenas ficcionales de lectura que se representaron en el Semanario, eran los "párrocos ilustrados" y el "ciudadano patriota" (Di Stefano, 2004; Barral, 2007; Maggio-Ramírez, 2008; Martínez Gramuglia, 2009; Díaz, 2012). Ellos dejarían la soledad de su biblioteca para leer en voz alta y así dar a conocer los nuevos métodos agrarios que se publicaban en la prensa.

En un paso más audaz también se propuso que las lecciones de agricultura, establecidas a modo de catecismo de preguntas y respuestas, que prefiguraba el aprendizaje por la memorización, se las leyeran los párrocos a los niños para que ellos corrigieran a sus padres (Maggio-Ramírez, 2008; Martínez Gramuglia, 2009). Lo moderno, centrado en la escritura y el saber utilitario europeo, contra la tradición oral y el saber de transmisión 
generacional americano. El título del Semanario era en sí un programa de gobierno, la élite letrada encontró en la economía política un corpus literario que buscaba fomentar las "buenas costumbres", y a la vez cuestionar solapadamente al régimen político virreinal (Usoz, 2013).

\subsection{El prospecto}

Al publicar el "Prospecto" con anticipación se buscaban ganar suscriptores, que pagaran por adelantado el periódico. La apuesta era ganar previsibilidad monetaria pero también producir y gestionar contenidos con anticipación para una publicación semanal. El "Prospecto" del Semanario, al igual que el "Análisis" del Telégrafo, no tiene fecha de impresión. Se puede conjeturar que salió de la imprenta antes del 25 de julio de 1802, cuando aún se publicaba el Telégrafo Mercantil. Juan Manuel Perdriel envió al Deán Gregorio Funes, clérigo erudito asentado en la Córdoba, una esquela fechada el 25 de julio en donde le agradeció los ejemplares recibidos de la "Carta crítica" y le anunció que

Don Juan Pablo [sic] Vieytes ha publicado un prospecto, para publicar un Semanario de Agricultura, industria, y Comercio, es un paisano aprovechado y sus deseos por el bien de la patria exigen la protección de los literatos, y pudientes. Yo le he asegurado que debe contar con el favor de Ud. y por lo tanto le suplico que su contestación sea benévola, no dudo que la opinión de Ud. le proporcione suscriptores, y que le remitirán las noticias, y papeles que le puedan ser útiles a la América. Mis paisanos están empeñados en protegerle, auxilio que negaron a Cabello porque este pudo conseguir lo que a un patricio le fue negado, y en todas circunstancias es buena /... lación. (Archivo del doctor Gregorio Funes, 1944: 97)

La carta puso en evidencia los lazos asociativos entre literatos criollos y cómo era necesaria la validación de un erudito establecido y reconocido en el virreinato. La protección entre pares a través del comentario benévolo fue una de las formas para garantizar las futuras suscripciones al periódico. El adjetivo paisano refuerza el pedido de apoyo a la iniciativa del arequero; en tanto que Vieytes "es de un mismo país, provincia, o lugar que otro" (RAE, 1803: 610). ¿Fue este tipo de apoyo el que se negó, una vez aparecido el Semanario, a Francisco Cabello y Mesa en su Telégrafo Mercantil? La nación que comparten los periodistas se encontraba bajo la égida de los Borbones, pero es la patria, su origen americano, lo que marca la diferencia. Funes, Pedriel y Vieytes son paisanos en tanto criollos nacidos en el sur del virreinato del Perú antes de que fuera desmembrado por las reformas borbónicas.

Era preciso hacer circular el "Prospecto" impreso con velocidad. El 28 de julio de 1802 se enviaron copias junto con el pedido formal por parte de Vieytes, quien solicitaba la protección del Consulado de Buenos Aires para la publicación del Semanario. El editor, al escribir al Consulado, recalcó que su intervención periodística buscaba la 
modificación de las costumbres porque el labrador repetía de sus padres saberes anquilosados. El Semanario prometía ser

un papel que sólo tiene por objeto el hacer florecer y prosperar a nuestra lánguida Agricultura y ver ocupados útilmente los brazos que hoy se hallan concentrados en la más reprensible ociosidad. Si SS VSS conocen mejor que nadie por una tan triste como lamentable experiencia cuanta necesidad tiene el Labrador de que se le enseñe prácticamente el camino que debe seguir en sus ejercicios rurales, y que por falta de este auxilio se mantiene como aislado dentro de los escasos conocimientos que le enseñaron sus Padres. (AGN, Documentos Escritos. Sala IX. Legajo 4 - 7 - 6).

La promoción del periódico también implicó a la burocracia virreinal más allá de la ciudad portuaria. El virrey de Buenos Aires, Joaquín del Pino y Rozas envió una carta, fechada el 25 de julio de 1802, junto con cuatro ejemplares del "Prospecto" del Semanario al gobernador e intendente del Paraguay, Lázaro de Ribera y Espinoza de los Monteros. El virrey deseaba

[...] ver mejoradas en lo posible la Agricultura e Industria de estas Provincias y que á la inacción y ociosidad suceda el laborioso afán, y creyendo que en mucha parte podría proporcionar este justo objeto la edición de un Papel Público que instruya, y estimule al trabajo, he concedido permiso a D. Juan Hipólito Vieytes para que pueda imprimir en esta Capital un Periódico con el título de Semanario de Agricultura, Industria y Comercio, bajo la inmediata revisión y censura del Sr. Asesor general D. Juan de Almagro, y para que la unidad que puede acarrear este periódico sea extensiva a todas las provincias del virreinato, recomiendo al acreditado celo de V. S. cuide de que se difunda por todos los partidos de su mando para que se logre conseguir el fin que tiene por objeto de unir en general los conocimientos de las mejores producciones, y contraerse al fomento, aplicación y destino de los ramos que pueden constituir la común prosperidad. (SAIC, 1928a [1802]: 94).

Esas líneas, que se conocen porque Lázaro de Ribera le escribió a Vieytes una carta donde comentaba, con fecha del 27 de septiembre, sobre sus esfuerzos para propagar el Semanario con la certeza de la utilidad de los conocimientos que se prometían divulgar. Los cuatro ejemplares del "Prospecto", que despachó el virrey junto con su carta, se hicieron circular entre los "vecinos más acomodados"3.

\footnotetext{
${ }^{3}$ La vecindad no se definía en el siglo XVIII por la cercanía en la ciudad, sino que era sinónimo de ciudadano en tanto era "el vecino de una ciudad que goza de sus privilegios, y está obligado a sus cargas", según el Diccionario de Autoridades en 1725. En la urbe, los vecinos "eran hombres libres que se ubicaban entre los artesanos que estaban abajo y los nobles, los oficiales reales y los curas que estaban arriba. La particularidad de la sociedad rioplatense virreinal es que los vecinos de prestigio ocuparon el lugar de la
} 
Los límites temáticos, encarnados en el título, pronto fueron ampliados al caer en desgracia el Telégrafo Mercantil. El 16 de febrero de 1803 se publicó en el Semanario una "Nota" donde el editor anunciaba que además de la agricultura, industria, comercio y educación, temas que había anunciado en el "Prospecto", se sumaban aquellas noticias que fueran de interés para el público (SAIC, 1928a [1803]: 176). Tiempo después, en contestación a una epístola de Casimiro Chegre -en la que se cuestionaba a los médicos por recetar en latín y con abreviaturas ilegibles-, Vieytes recordó que ya había anoticiado a su público que ampliaba los límites del título del periódico para publicar aquellos contenidos. El objetivo del Semanario se ampliaba para fomentar el bienestar y a la conservación de la salud (SAIC, 1928b [1804]: 287). El cuidado de la salud fue crucial para el proyecto ilustrado, ya que la correlación entre agricultura, industria y comercio sólo era eficaz si se contaban brazos sanos para enfrentar los distintos trabajos. La salud individual como la social, que también apuntaban a un aumento poblacional en tanto "riqueza de las naciones", así como la literatura de civilidad fueron los ejes del Semanario, más allá de los límites de su nombre.

\section{Las fuentes de información para los temas del "Prospecto"}

Sin pudor, Vieytes afirmó en su "Prospecto" que tenía "a la vista a los mejores Autores así Nacionales como Extranjero", para dotar de contenidos al impreso. No sólo hacía referencia a los libros sino a "los mejores periódicos de Europa (a los que ya [se había ...] subscrito con anticipación)". También hizo hincapié en el establecimiento de un canal de comunicación con sus lectores, al prometer recibir e insertar en su impreso aquellas memorias que se le "remitan (francas de porte) con tal que en ellas se trasluzca la utilidad que tiene por objeto este periódico" (SAIC, 1928a [1802]). Libros, periódicos y las memorias, de los lectores, fueron las principales fuentes de contenidos para el Semanario de Agricultura porteño.

La historiografía sobre la cultura impresa que contestó la pregunta por las fuentes de información de la prensa virreinal, lo hizo con distintas intensidades. La Efemeridografía argirometropolitana hasta la caída del gobierno de Rosas de Antonio Zinny de 1869, si bien es de tono descriptivo sobre los artículos y temas que se trataron, destacó que se

nobleza faltante" (Casanello, 2008: 20). El vecino de las reformas borbónicas era "un sujeto corporativo, elector de autoridades y habilitado para postularse a cargos electivos; por eso no existía ciudadanía en el mundo rural donde no había elecciones ni autoridades elegibles" (Casanello, 2008: 22). Puede suponerse entonces que los restantes lectores del "Prospecto" en el Paraguay fueran ciudadanos que podrían cumplir con la propuesta de Vieytes para oficiar de mediadores de la cultura impresa. 
incorporaron memorias, informes y cartas de lectores, y que se extractaron textos del Mercurio Español de 1802 así como de la gaceta inglesa The Naval Chronicle. Años después la investigación de José Toribio Medina (1892) sobre la imprenta en el virreinato del Río de la Plata intentó responder el mismo interrogante cuando transcribió fragmentos de la biografía sobre Vieytes escrita por Clemente L. Fregeiro, que tras leer el Semanario, sostuvo que los suscriptores terminaron "leyendo á Ustáriz, Zavala, Campillo, Jovellanos, Foronda, etc. entre los nacionales; y á Galiani, al Marqués de Mirabeau, al hombre de Estado, y al sublime economista Adam Smith, entre los extranjeros [...]" (Medina, 1892: 177). Félix Weinberg (1956) en su exhaustivo trabajo para reponer la biografía, analizar el trabajo editorial de Vieytes, así como la selección de artículos del Semanario, amplió la lista de nombres que aparecen en el periódico y de los que presume fueron conocidos en "lectura directa"

Entre los pensadores y políticos, encuéntranse Montesquieu, Ulloa, Nickols, Arnold, Pauw; entre los científicos, Buffon, Linneo, Hales, Berthollet, Lavoissier, Fourcroy, Vauquelin, Chaptal, Rumford, Jenner, Reamur, Parmentier, Guthrie, Cadet de Vaux y tal vez Paracelso; y además Benjamin Franklin, de quien reprodujo numerosos artículos. En cuanto a los economistas, conoció a Jovellanos, Ustariz, Zabala, Campillo, Foronda, Ward, y Galiani, el marqués de Mirabeau, el abate Morellet, La Ribière, Hume, y desde luego Adam Smith. Del célebre autor de las Investigaciones de la naturaleza y causa de la riqueza de las naciones publicó una larga exposición de sus ideas, según la interpretación de S. Crumpe, que ocupa gran parte del tomo tercero del Semanario (Weinberg, 1956: 18).

Al ampliarse el relevamiento de autores cuyos nombres fueron citados en el Semanario, respecto del realizado por Fregeiro, quedaba pendiente contrastar con el inventario de la biblioteca de Vieytes. En una addenda al ensayo "Vieytes y la Revolución”, Weinberg (1956: 78) manifestó que halló una glosa del expediente sobre el embargo de los bienes de Vieytes en el periódico El Día de 1920 cuando ya se encontraba en su investigación "en pruebas de páginas".

Con posterioridad a la publicación de Weinberg, ese mismo año se entregó a imprenta el ensayo de José Torre Revello (1956) que incluía el detalle del inventario de la biblioteca. Torre Revello (1956: 73) sostuvo que Vieytes "comentó, reprodujo y extractó artículos insertos en "papeles públicos" más importantes de Europa y América que podían leerse en Buenos Aires, lo que viene a confirmar que no eran tan restringidas las lecturas, como han supuesto algunos autores que no han profundizado sobre el tema". Acto seguido listó los periódicos que aparecen nombrados en el Semanario:

Annales des arts et manufactures; Journal d'economic rurale, "uno de los mejores papeles públicos de Europa"; Journal de Paris; Journal des arts et manufactures; Gazette Nationale ou le Moniteur Universel, París; L'esprit des journalistes, de Trevoux; Gazeta de Lisboa; Anales de literatura, ciencia y artes; Correo Mercantil, 
de Madrid; Diario de Madrid; Espíritu de los mejores diarios; Gazeta de Madrid; Gazeta de la Salud; Mercurio de España; Semanario de agricultura y artes de Madrid. Entre los periódicos americanos, figuran: Gaceta de Lima; Mercurio Peruano; Minerva Peruana; Papel Periódico de la Ciudad de Santa Fe de Bogotá. Entre otras hojas mencionadas en el Semanario, en forma imprecisa o bien castellanizándolos los títulos, figuran: Gazeta extranjera, Papel público de Londres, Gazeta de Bayona, Gazetas inglesas, Gazeta de Filadelfia [... y] The naval chronicle (Torre Revello, 1956:73)

Tanto Weinberg como Torre Revello dieron por cierto que Vieytes había tenido acceso directo a las fuentes que citaba. No necesariamente por la posesión de los periódicos sino a través del préstamo, que fue una práctica usual al interior de la cultura letrada virreinal; como lo demostró Alejandro Parada (2002) al analizar el cuaderno de préstamos de libros de Facundo de Prieto y Pulido. Al insertarse Torre Revello y Weinberg en un panorama historiográfico que tenía como norte rescatar, transcribir y editar documentos de distintos repositorios nacionales e internacionales no generaron dudas sus afirmaciones entre los investigadores que les siguieron (Maggio-Ramírez, 2008; Martínez Gramuglia, 2009, Rojas, 2010, entre otros). Probablemente los estudios anteriores imaginaron que ante la falta de concordancia entre el inventario de Vieytes y las citas de periódicos en otras lenguas los mismos se extraviaron de la librería del editor, entre la fecha de salida del Semanario y el relevamiento del inventario; entre muchas otras posibilidades.

\section{La traducción como problema}

Para desmontar los errores de atribución por parte de la historiografía hizo falta desandar una vieja pregunta para tomar nuevos caminos. Cuando se respondió por las fuentes en las que abrevó Vieytes, se hizo hincapié en aquellos nombres que aparecían en las notas al pie de cada artículo, con el nombre del periódico extranjero (en algunos casos sin la grafía correcta), pero nunca se dudó de la traducción del editor como mediador entre Europa y Buenos Aires.

El proceso de digitalización de la información, el abaratamiento de hardware, el acceso a internet y el auge de los estudios sobre historia de la cultura impresa, fueron algunas variables que posibilitaron la conformación de repositorios digitales sobre prensa periódica, que hasta hace pocos años sólo se podía consultar en microfilm. Ante la sospecha de la traducción como una de las actividades del editor se rastrearon aquellos artículos que se atribuían a una fuente periódica pero que no se encontraba entre las que se hallaron en el inventario de Vieytes. Luego se comparó el segundo párrafo, ya que en el primero se solía introducir el artículo a los lectores locales, con los periódicos 
alojados en la Hemeroteca Digital de la Biblioteca Nacional de España. También se compararon algunos párrafos con los libros digitalizados en Google Books, cuando no se encontraban coincidencias en la Hemeroteca Digital. Este simple proceso permitió realizar la correcta atribución de las fuentes que sirvieron de ayuda para dotar de contenidos el Semanario de Vieytes.

En los primeros cuatros tomos del periódico, hasta la primera invasión inglesa, se sospechó que la mención de un periódico extranjero en francés o inglés era en realidad una copia de la traducción realizada por algún periódico español. Las principales fuentes fueron El Correo Mercantil de España y sus Indias, el Semanario de Agricultura y Artes dirigido a los párrocos y el Espíritu de los mejores diarios que se publican en Europa. Los dos últimos se encontraban en el inventario de la biblioteca de Vieytes realizado en 1815.

En el primer tomo del Semanario se halló en el número 9, folio 71, una nota al pie que retomaba los preceptos de Adam Smith al afirmar que "una nación no es poderosa por el espacio que ocupa en el globo, sino por su población, su trabajo y su industria", y Vieytes sostuvo que tal afirmación provenía de "un papel público de Londres de 15 de Diciembre de 1799 en el que se dice lo siguiente". La cita que seguía no fue tomada de un periódico inglés ni traducida por Vieytes sino de periódico El Correo Mercantil de España y sus Indias, fechado el 21 de enero de 1799 en su página $3^{4}$.

Además de transcribir traducciones sin mencionar el origen de la misma, vale aclarar que hubo casos en los que se atribuyó su procedencia, aunque sin indicar la fecha del impreso. En el Correo Mercantil hubo un profundo interés por enseñar los métodos para teñir lanas, obtener tintas y óleos de distintos colores. En el Semanario (1928a [1803]: 143) se publicó “Método para hacer un hermoso color amarillo para pintar al óleo, por el Ciudadano Dupont", y sólo se indicó al final la abreviatura Corr Merc que avisaba que había sido tomado del Correo Mercantil. En ese periódico se publicó el 25 de marzo de 1799 y al año siguiente fue recuperado en Madrid desde el tomo nueve de la Miscelanea Instructiva, curiosa y agradable o anales de literatura, ciencias y artes. Sacados de los mejores escritos que se publican en Europa en diversos idiomas, en la imprenta de Antonio Cruzado. Es decir, la práctica de la transcripción de una fuente reciente no era inusual en la prensa hispanoamericana. Los periódicos, gracias a que se pensaba en su encuadernación futura, para su resguardo en una biblioteca (por la numeración corrida de la paginación y el índice impreso al final del tomo) nos indicaba que no era un producto efímero. Se leía pasados los años porque el concepto de novedad no estaba

\footnotetext{
${ }^{4}$ En la Biblioteca Digital Hispánica de la Biblioteca Nacional de España se encuentran disponibles los números entre las siguientes fechas: 01/10/1792 al 30/06/1808.
} 
atado al de inmediatez temporal sino al de modernidad, al quiebre con un antiguo régimen.

El 13 de abril de 1803, Vieytes transcribió el texto "Nuevo método de hacer el carbon", que lo tomó del Semanario de Agricultura y Artes dirigido a los párrocos ${ }^{5}$, que a su vez lo había extractado de Annales des arts et manufactures, tomo V, según reza en la fuente española pero no informada en su versión porteña. El editor supo indicar en diferentes artículos que el texto fue "copiado" o "sacado" del Semanario madrileño pero no así cuando era una traducción realizada en España. En Buenos Aires se leyó "De los incendios espontáneos y precauciones contra ellos", gracias a que se transcribió del Semanario ibérico del 20 de mayo de 1802, así como también "De los incendios espontáneos y precauciones contra ellos", que fue extractado del número 20 de los Annales des arts et manufactures que Vieytes lo copió el 9 de enero de 1804, sin dar cuenta una vez más de la traducción (SAIC, 1937a [1805]: 150).

La misma estrategia, eludir la mediación española y presentar el texto en castellano como si fuera una traducción propia, se replicó en el artículo "Del modo de teñir la madera de nogal para que imite perfectamente a la caoba" (SAIC, 1937b [1806]: 214) al indicar la fuente de origen en el "Journal des arts et manufactures", $\mathrm{n}^{\circ} .50$, cuando se publicó en castellano el 19 de julio de 1804 en el Semanario español. La misma estrategia se utilizó con el artículo "Modo de precaver el peligro del ayre mortal que se encuentra a veces en los pozos, minas, sótanos, cuevas etc", (SAIC, 1928b [1804]: 325), que se atribuyó su origen al impreso de la "Junta de Agricultura y Artes de París", cuando era una réplica del publicado en el Semanario madrileño el 25 de agosto de 1803. En el tomo III, en el número 119 del Semanario porteño se retomó esa temática por lo que el editor declaró que "[...] insertaré el que más se recomienda en uno de los mejores papeles públicos de Europa" para citar en nota al pie "Journal d' economíe rural" 6 . El artículo en cuestión fue traducido por el Semanario español el 21 de junio de 1804, en su número 390 y de allí copiado en Buenos Aires pero sin dar cuenta de la mediación del francés al castellano.

El 4 de abril de 1804 se publicó en Buenos Aires "Juguetes perjudiciales a la salud de los niños", sin que se indique su origen. Simplemente antes de entrecomillado se lee: "Por encargo de la policía de París examino una junta de médicos los colores de que están pintados diferentes juguetes que se suelen dar a los niños, y dieron el informe siguiente" (SAIC, 1928b [1804]: 245). No se mencionó la fuente en la que se abrevó pero se rastreó

\footnotetext{
${ }^{5}$ En la Biblioteca Digital Hispánica de la Biblioteca Nacional de España se encuentran disponibles del Semanario los números entre las siguientes fechas: 01/01/1797 al 23/06/1808.

${ }^{6}$ Probablemente las referencias del Semanario ibérico a la Junta de Agricultura y Artes de París y al Journal d' economíe rural, hagan referencia a las Mémoires d'agriculture, d'économie rurale et domestique que se comenzó a publicar en 1785 por la Real Sociedad de Agricultura de París.
} 
su traducción en el número publicado por el Semanario de Agricultura y Artes del 6 de enero de 1803.

En síntesis, cuando se citó en el Semanario porteño que los contenidos habían sido tomados de periódicos franceses eran transcripciones de las traducciones que se había realizado en España para el Semanario de Agricultura y Artes dirigido a los párrocos pero también del periódico de Cristóbal Cladera: el Espíritu de los mejores diarios ${ }^{7}$. Por ejemplo, se indicó que "Cálculo político sobre la población de todo el mundo" había sido tomado del Alamake de Lisboa y que "Si la comedia corrige las costumbres" era una carta escrita a los autores del Diario de París cuando en ambos casos fueron tomados del Espíritu de los mejores diarios, que se encontró en la biblioteca del editor.

Los casos de transcripciones se repiten. No es aquí la intención de establecer un control bibliográfico, sino indagar cuál fue el marco dentro de la historia de la cultura impresa que avaló la circulación del conocimiento; y borró las huellas de la traducción, cuando la fuente de origen era un periódico.

La omisión de la fuente de origen no sucedió cuando esta era un libro. Principalmente los diccionarios enciclopédicos, que en castellano y francés se hallaron en la biblioteca de Vieytes, fueron citados cuando se realizó una breve traducción. Muy probablemente tomó del Dictionnaire Oeconomique de Nöel Chomel, una receta para elaborar tinta china y la tradujo al castellano. Al final del artículo esbozó la referencia del origen "Dic. Ec." (SAIC, 1928a [1803]: 393) que solo se pudo reponer la sospecha al consultar el inventario de su biblioteca. En las "Lecciones elementares [sic] de agricultura por preguntas y respuestas, para el uso de los jóvenes de estas campañas" reconoció las fuentes de origen para la realización de la cartilla en una nota al pie.

Aunque en la formación de esta Cartilla hemos procurado seguir el método del P. Gorte en sus lecciones elementales de agricultura, de quienes hemos extractado y traducido muchas lecciones; y aunque consultando al mejor acierto se han tenido a la vista varios prácticos, como son, la agricultura general y gobierno de la casa de campo de D. Joseph Antonio Valcarcel; el Agrónomo ó Diccionario del cultivador, a Mr. Duhamel, el curso completo de agricultura de Rozzier; el semanario de agricultura y artes de Madrid, y muchas otras memorias y disertaciones sueltas, escritas en estos tiempos; sin embargo estamos muy distantes de persuadirnos que no se adviertan en ella mil defectos, que pudieran haberse corregido de algun modo si hubiera habido el tiempo necesario para que la examinasen los prácticos agricultores. (SAIC, 1928a [1803]: 345)

\footnotetext{
7 El Espíritu ... se encuentra disponible en la Hemeroteca digital de la BNE entre el 02/07/1787 y 14/02/1791.
} 
El "Prospecto" marcaba una ruptura temporal con el saber tradicional cuando Vieytes escribió "[y]a es llegado el tiempo en el que la voz del sabio [...] se dexe oir distintamente en el centro de nuestras modernas poblaciones" (SAIC, 1928a [1802]). Ese quiebre temporal con la llegada del impreso periódico lo retomó en la nota al pie de las lecciones. Allí escribió que esos textos eran de "estos tiempos" para "modernas poblaciones". Nuevo y moderno se aglutinaron como sinónimos. El auge de la traducción española, en tiempos de la ilustración borbónica, en temas como la salud pública, la cuestión agraria y demás saberes técnicos tuvo sus lectores en América ${ }^{8}$. Los impresos que citó Vieytes se comenzaron a publicar a fines del siglo XVIII como por ejemplo la obra Agricultura general y gobierno de la casa de campo de José Antonio Valcárcel se imprimió en 1765, el Curso completo ó Diccionario universal de agricultura teórica, práctica, económica, y de medicina rural y veterinaria, del abate Rozier se comenzó a publicar en 1797, en el mismo año que el Semanario de Agricultura y Artes.

Desde los confines del imperio borbónico se elucubraron estrategias discursivas para acercarse desde la periferia al centro de la cultura letrada española. Vieytes citó las últimas producciones bibliográficas y periódicas en castellano. En aras de forzar la construcción ficcional del acceso a la información "moderna", como si estuviese en España, evitó mencionar las traducciones que realizó la prensa periódica española de los papeles públicos europeos.

\section{Los periódicos como lugares comunes}

Se creyó durante más de una centuria que la traducción en la prensa tardocolonial fue una práctica usual por parte de los editores y que el comercio de un puerto marcado por el contrabando facilitaba la llegada de diversos impresos periódicos en lenguas distintas al castellano. Estas afirmaciones se pueden apaciguar frente a los resultados que demostraron que antes de traducir fuentes francesas, inglesas o portuguesas, en Buenos Aires se leyó y transcribió la prensa en castellano.

Francisco Cabello y Mesa, y Juan H. Vieytes, cada uno a su manera lo advirtió. El primero afirmó en el "Análisis" del Telégrafo Mercantil que "muchas veces vomitaré párrafos enteros de mis libros tan íntegros, y perfectos como la ballena a Jonás en los campos de Nínive; pues no deja de ofrecerme que para empresa tan basta, necesito de un estómago de tanto buque como el de aquel vizcaíno del que habla el diario pinciano de Valladolid, so pena de exponerme a mortal apoplegía". El arco metafórico utilizado por

\footnotetext{
${ }^{8}$ La traducción en la España dieciochesca fue abordada por Pinilla (2009) y Lafarga (2014), entre otros autores.
} 
el extremeño iba desde la lectura como alimento hasta la escritura como consecuencia excesiva del abuso lector. La lectura como alimento tiene una larga tradición en las religiones del libro, especialmente en las judeo-cristianas. Comer el fruto prohibido abre el camino al saber, comer el libro es leerlo pero también es memorizarlo, hacerlo cuerpo. Margit Frenk (2006) señaló que "[l]a asociación de la lectura con la alimentación -y no es casual el que a lo largo de los siglos se haya escuchado leer durante la comidaaparece en el Antiguo Testamento ('comer el libro' 'memorizarlo', Ezequiel: Jousse, 1981, 205-206) en muchos monjes medievales, que hablan del palatum cordis, de ruminatio, de 'sabor'". Para vomitar sobre las páginas del Telégrafo, Cabello debería leer bajo el compromiso de no alterar los párrafos de otros que copiaría en su impreso. La promesa de mantener los textos "íntegros y perfectos" se puede anudar con los cuadernos manuscritos de lugares comunes. La escritura de fragmentos, citas, o bien impresiones tras la lectura era una práctica que puede pensarse heredada desde el siglo de Oro español donde los cuadernos de lugares comunes tenían tanto fines didácticos como de ayuda memoria para los doctos por lo que el periódico en el siglo XVIII fue heredero de esa tradición. Contagiar las lecturas de textos ajenos al fomentar su circulación, aunque no siempre aparezca la mención de la fuente correspondiente o el autor de la obra que es glosada, era una de las tareas de la prensa tardocolonial porteña.

Cabello y Mesa en el Telégrafo, Vieytes en el Semanario, y Belgrano en el Correo de Comercio, usualmente transcribieron textos de la prensa española sin indicarlo para demostrar que estaban al corriente de lo que sucedía en la comunidad letrada francesa. La traducción, al presentarla como propia, implicaba no sólo el conocimiento directo de la fuente sino la certeza que la apropiación estaba validada porque se apelaba a la utilidad de esos saberes en favor del bien público y así cumplir con los objetivos del periódico.

La utilidad del saber en favor del bien común y el derecho de la propiedad literaria quedaron expuestos por Roger Chartier (2006) cuando analizó la tensión entre las posturas Denis Diderot y Condorcet. El marqués de Condorcet, que no vivía de sus escritos, aseguró que la propiedad literaria era un "privilegio" que socavaba el interés público porque es "una traba impuesta a la libertad, una restricción a los derechos de los otros ciudadanos [para que ...] cada uno pueda libremente componer, mejorar, reproducir, difundir las verdades útiles a todos; de ninguna manera pueden ser objetos de una apropiación individual" (Chartier, 2006: 233). La propuesta del Semanario porteño se centró en cambiar las costumbres para lograr una mejora en la producción agropecuaria, de acuerdo a los dictámenes de la economía política dieciochesca. En ese gesto se trató de fortalecer la idea, entre la comunidad lectora, que los contenidos estaban a tono con las discusiones europeas. Desde el "Prospecto" el editor anunció que tendría 
a la vista los mejores autores así nacionales como extranjeros que en estos últimos tiempos ilustrados hayan tratado con más conocimiento sobre las materias indicadas. Consultaré los mejores periódicos de Europa (a los que ya me he suscripto con anticipación) para comunicar al público los conocimientos útiles que puedan fácilmente acomodarse a nuestra situación actual [...] (SAIC, 1928a [1802]).

Para cumplir con la promesa del "Prospecto" el editor decidió indicar los periódicos extranjeros, en los que abrevó el Semanario madrileño, sin reponer la mediación de la traducción. Vieytes, se podría sostener, que siguió el consejo que glosó Saturnino Segurola en su "Fruto de mis lecturas" de Nicolás Jamin, cuyo Verdadero antidoto contra los malos libros de estos tiempos se publicó en 1784. En la entrada "Escribir" se recomendaba leer con la pluma en la mano para

extraer lo que se encuentra de bueno y útil, respecto a la ciencia que se profesa por su estado, o por gusto, trae consigo muchas ventajas: ella estimula, y anima la atención del lector, y hace a la lectura más profunda: facilita la inteligencia de las cosas, que se imprimen mas en la memoria con la repetición de su lectura, y es un excelente remedio contra el olvido (Segurola, AGN, BN, 53).

La prensa virreinal necesitó de la omisión sobre sus fuentes de información para enmascarar su modernidad y centralidad en la circulación del saber útil y operacional para modificar las costumbres de aquellos que escucharían leer a viva voz los textos que se copiaban. Vieytes, al igual que Manuel Belgrano, fue un lector voraz que copió y transcribió sus lecturas para compartirlas con sus pares porque creían así que favorecían el bien común.

Es decir, el modelo del periodista-compilador que estuvo presente en la prensa española de finales del siglo XVIII también se replicó en el Río de la Plata (Larriba, 2014). Si el editor del Correo Literario de la Europa, guardaba la esperanza de publicar con un retraso de no más de dos meses las noticias de Europa, Vieytes tenía que esperar un poco más pero coincidieron en dar cuenta a sus lectores del esfuerzo económico que hacían al suscribirse a publicaciones extranjeras (Larriba, 2014).

Si la prensa extranjera era en España una fuente privilegiada y poco difundida, en los extremos de América se buscaron estrategias para acortar las distancias simbólicas gracias a las traducciones que se realizaron para el público español. 


\section{Conclusiones}

Al revisar las fuentes de información citadas en el Semanario de Agricultura, Industria y Comercio se concluyó que cada vez que se citó un periódico francés no se tuvo acceso al mismo. Se compararon las traducciones de los artículos, que remitían a una fuente de origen en francés, con los textos de artículos digitalizados en el repositorio de la Hemeroteca Digital de la Biblioteca Nacional de España. Al encontrarse coincidencias se pudo concluir que Vieytes transcribió las traducciones que de las fuentes francesas se habían publicado con anterioridad en el Semanario de Agricultura y Artes dirigido a los párrocos y de El espíritu de los mejores diarios. Esta estrategia para dotar de contenidos al periódico se comprende a principios del siglo XIX para cumplir con la periodicidad semanal prometida a los suscriptores. Los tiempos de la imprenta manual implicaba contemplar el trabajo de los componedores, la impresión propiamente dicha, la circulación del periódico por lo que la gestión del contenido necesitaba de un flujo constante de información que se encontró en los tomos ya encuadernados de los periódicos españoles.

Desde la historia de la cultura impresa y gracias a los desarrollos de las humanidades digitales se facilitó el acceso a fuentes para corregir las atribuciones erróneas que la historiografía sobre la prensa y la cultura del siglo XIX mantuvieron vigentes durante años. La historiografía tradicional se dedicó a rastrear la literatura francesa en los inventarios de bibliotecas virreinales para establecer una relación directa entre la lectura y el proceso revolucionario de Mayo de 1810 (Caillet-Bois, 1929). El enfoque determinista, que encontraba la causa de las revoluciones atlánticas en la revolución francesa, fue descartado desde la historiografía política, sus marcas perduraron. Hasta entrado el siglo XXI se sostuvo que en Buenos Aires la literatura periódica en francés circulaba y era traducida por los letrados locales. El trabajo antecedente demostró que la labor de traducción como principal activo para la gestión de contenidos no fue propia de los eruditos durante el virreinato, sino que para cumplir con los tiempos de publicación semanal abrevaron en la prensa española.

La estrategia de evitar la mención de la fuente de origen de la traducción de un periódico francés tenía su tradición en el mundo del libro. La investigación de Inmaculada Urzainqui (1991) denominó a la traducción subrepticia o semisubrepticia cuando "aquellas obras que, constándonos ser traducidas, o sacadas de obras extranjeras, no aparecen como tales en la portada, o sólo de una manera imprecisa y vaga, sea por razones de censura, sea por el prurito de parecer original, sea por falta de conciencia de autoría, o por otros motivos" (Urzainqui, 1991: 625). Desde el "Prospecto", cuando se anunció que se tendrían a mano los periódicos europeos, se reconocía que la producción no sería original en el pacto ficcional entre los futuros suscriptores y el editor. Borrar la fuente originaria que había realizado la traducción era menos doloso, para el espíritu de la época, que hacerlo de un libro. 
La circulación de libros y periódicos en Buenos Aires fue el principal basamento para dotar de contenidos al periódico, más allá de los textos originales que presentaron los colaboradores. Las largas listas de autores y libros que se creyó fueron consultados de forma directa, porque se estimaba su circulación y lectura en Buenos Aires se acotó radicalmente al condensarse en los periódicos españoles. La agenda de fragmentos de libros y artículos que se publicaron pueden leerse como una variante del género del cuaderno de lugares comunes. No está organizado de forma alfabética ni se limita a pequeños fragmentos sino es el signo de los intereses que Vieytes creyó necesario compartir con sus suscriptores. Leer para realizar la curaduría del contenido para su publicación y en ese gesto acortar las distancias entre Buenos Aires y Europa.

El periodismo virreinal porteño no se encontró urgido por la novedad y el acontecer de los hechos; al menos hasta la primera invasión inglesa. El tomo 5 del Semanario no solo recuperó los ecos de la primera invasión inglesa sino que también fue la caja de resonancia local de la política internacional. La traducción, frente a la urgencia de los hechos, se presume se realizó de periódicos sueltos, sin la encuadernación en tomos que compilaban al menos seis meses de números publicados. Queda para una instancia futura abordar el tomo que publicó entre 1806 y 1807 para rastrear el origen de las fuentes de información. La autoría y la traducción es un problema todavía abierto en la cultura impresa americana para corroborar con las herramientas digitales la atribución autoral como las traducciones, a la vez que ayuda a encontrar cuáles fueron los impresos que circularon por Buenos Aires aunque no se encuentren registrados en inventarios testamentarios o en donaciones de bibliotecas. Volver sobre principio del siglo XIX implica recordar que hubo un momento en que la información se pensó en favor del bien común, un valor que todavía resuena como un eco lejano en el presente.

\section{Referencias bibliográficas}

\section{Fuentes y archivos}

DOCUMENTOS ESCRITOS: Archivo General de la Nación (AGN), Sala IX. Legajo 4 - 7 - 6.

SEGUROLA, S. (sine data): Apuntes varios sobre física, química, historia natural y demás ramos profanos pertenecientes al estudio del D. D. Saturnino Segurola. Se puede Ilamar con propiedad esta obra Fruto de mis lecturas, Archivo General de la Nación (AGN), BN, 53, Buenos Aires.

SEMANARIO DE AGRICULTURA, INDUSTRIA Y COMERCIO. (1928a): Buenos Aires: Junta de Historia y Numismática Americana. (Reimpresión facsimilar, Vol. 1) 
(1928b): Buenos Aires: Junta de Historia y Numismática Americana. (Reimpresión facsimilar, Vol. 2)

(1937a): Buenos Aires: Junta de Historia y Numismática Americana. (Reimpresión facsimilar, Vol. 3).

(1937b): Buenos Aires: Junta de Historia y Numismática Americana. (Reimpresión facsimilar, Vol. 4).

\section{Bibliografía}

BARRAL, M. E. (2007). «Disciplina y civilidad en el mundo rural de Buenos Aires a fines de la Colonia». Jahrbuch für Geschichte Lateinamerikas = Anuario de Historia de América Latina ( JbLA ), n.ㅇ 44 , pp. 135-155.

CAILLET-BOIS, R. R. (1929). Ensayo sobre el Río de la Plata y la Revolución Francesa.

Buenos Aires: Facultad de Filosofía y Letras. Universidad de Buenos Aires.

CASANELLO, O. C. (2008): Ciudadano/Vecino. En N. Goldman (Ed.), Lenguaje y revolución: Conceptos políticos clave en el Río de la Plata, 1780-1850. Buenos Aires: Prometeo Libros.

CHARTIER, R.. (1994): "Textos, impresos, lecturas". En Libros, lecturas y lectores en la Edad Moderna, Madrid: Alianza, pp. 41-57.

CHARTIER, R. (2006): Epílogo. Diderot y sus corsarios. En Inscribir y borrar. Cultura escrita y literatura (siglos XI-XVIII) (pp. 215-238). Buenos Aires: Katz.

CHIARAMONTE, J. C. 2007. La Ilustración en el Río de la Plata. Cultura eclesiástica y cultura laica durante el Virreinato. Buenos Aires: Sudamericana.

CLÉMENT, J.-P. (1997): El Mercurio Peruano 1790-1795. Estudio. (Vol. 1). Frankfurt am Main: Vervuert.

CORREA LUNA, C.; MALLIÉ, A. y ZABALA, R. (1928). "Advertencia" en Semanario de Agricultura, Industria y Comercio. Vol. 1. Buenos Aires: Junta de Historia y Numismática Americana, pp. 17-27.

DI STEFANO, R. (2004). El púlpito y la plaza: clero, sociedad y política de la monarquía católica a la república rosista. Buenos Aires, República Argentina: Siglo Veintiuno Editores Argentina.

DÍAZ, C. L. (2012): Comunicación y revolución, 1759-1810: Esfera y espacio público rioplatense: periodismo, censura, prácticas y ámbitos de lectura. La Plata, Provincia de Buenos Aires, República Argentina: Ediciones de Periodismo y Comunicación. 
DÍEZ RODRÍGUEZ, F. (2001): Utilidad, deseo y virtud: La formación de la idea moderna del trabajo (1. ed). Barcelona: Ediciones Península.

FERNÁNDEZ LÓPEZ, M. (2005). “Cartas de Foronda: su influencia en el pensamiento económico argentino", Disponible en Internet (6/4/2021): https://aaep.org.ar/anales/works/works2005/fernandezlopez.pdf

LAFARGA, F. (2014). "Tendencias de la traducción de autores del XVIII francés en España (1975-2013): consideraciones en torno a un catálogo", en Anales de filología francesa, n.ㅇ 22, pp. 161-175.

LARRIBA, E (2005). "L'art au service de la divulgation scientifique: le rôle des gravures dans le "Semanario de Agricultura y Artes dirigido a los Párrocos" (1797-1808)». Disponible en Internet (6/4/2021): http://argonauta.imageson.org/document57.html

LARRIBA, E. (2013). El público de la prensa en España a finales del siglo XVIII (1781-1808). 1.a edición. Zaragoza: Prensas de la Universidad de Zaragoza.

LARRIBA, E. (2014). "La presse espagnole à la fin du XVIlle siècle: De l'appel à collaboration à la tentation du plagiat". El Argonauta español. https://doi.org/10.4000/argonauta.1997

LARRIBA, E. y DUFOUR, G. (1997). "Introducción” en El Semanario de agricultura y artes dirigido a los párracos (1797-1808). Valladolid: Ámbito, pp 9-64.

FERNÁNDEZ ARMESTO, M. V. (2005): "Lectores y lecturas económicas en Buenos Aires a fines de la época colonial". Información, Cultura y Sociedad, 13, pp. 29-56.

FERNÁNDEZ LÓPEZ, M. (2005). Cartas de Foronda: Su influencia en el pensamiento económico argentino. Presentado en Reunión Anual de la Asociación Argentina de Economía Política, La Plata. Disponible en internet (8/12/2020) https://aaep.org.ar/anales/works/works2005/fernandezlopez.pdf

GUTIÉRREZ, J. M. (1866). “Bibliografía de la primera imprenta de Buenos Aires desde su fundación hasta 1810 inclusive, ó Catálogo con observaciones y noticias curiosas sobre las producciones de la imprenta de Niños Expósitos desde 1781 hasta 1810 (inédito)". La Revista de Buenos Aires, 9. Disponible en internet (8/12/2020) http://archive.org/details/larevistadebueno09buenuoft

MAGGIO-RAMÍREZ, M. (2008). “Un puro vegetar. Representaciones de la lectura en el Semanario de Agricultura, Industria y Comercio (1802-1807)" en BRUNETI, P. MAGGIO RAMIREZ, M. GRILLO, M. del C., Ensayos sobre la prensa: Primer Concurso de Investigación en Periódicos Argentinos en Homenaje al Prof. Jorge B. Rivera. Ciudad Autónoma de Buenos Aires: Biblioteca Nacional. 
MAGGIO-RAMÍREZ, M. (2020). "La circulación de saberes y el problema de la autoría en la prensa virreinal. Un análisis del Correo de Comercio, 1810-1811". Información, Cultura y Sociedad, 42, 11-34. https://doi.org/10.34096/ics.i42.7666

MAGGIO-RAMÍREZ, M. (2020a) “Un lector beligerante. Las lecturas de Manuel José de Lavardén". Anuario de estudios americanos, Vol. 77, n. 1, pp. 229-254.

MARTÍNEZ GRAMUGLIA, P. (2009). "El pensamiento agrario ilustrado en el Río de la Plata: Un estudio del Semanario de Agricultura, Industria y Comercio (18021807)". Mundo Agrario, 9(18). Disponible en internet (8/12/2020) http://www.memoria.fahce.unlp.edu.ar/art_revistas/pr.3777/pr.3777.pdf

MARTINI, M. P. (1998). Francisco Antonio Cabello y Mesa: Un publicista ilustrado de dos mundos (1786-1824). Buenos Aires: Instituto de Investigaciones sobre Identidad Cultural, Universidad del Salvador.

MEDINA, J. T. (1892). Virreinato del Río de la Plata III. Buenos Aires. En Historia y bibliografía de la imprenta en la América española. La Plata: Museo. Disponible en internet (8/12/2020) http://bdh.bne.es/bnesearch/detalle/bdh0000015003

PARADA, A. E. (2002): De la biblioteca particular a la biblioteca pública: Libros, lectores y pensamiento bibliotecario en los orígenes de la Biblioteca Pública de Buenos Aires 1779-1812. Buenos Aires: Instituto de Investigaciones Bibliotecológicas, Facultad de Filosofía y Letras, UBA.

PINILLA, J. (ed. lit) (2009). La traducción en la época ilustrada: (panorámicas de la traducción en el siglo XVIII). Granada: Comares.

ROJAS, R. (2010): El pensamiento económico de Juan Hipolito Vieytes. Buenos Aires: Fundación San Antonio.

SÁINZ, María Dolores (1983). «El resurgir de la prensa en los últimos años del siglo XVIII» en Historia del periodismo en España. Los orígenes. El siglo XVIII. Madrid: Alianza. Pp. 173-202.

SÁNCHEZ-BLANCO, Francisco (2013). «Periódicos» en La llustración y la unidad cultural europea. Pablo de Olavide. Madrid, Sevilla: Marcial Pons Historia; Fundación de Municipios Pablo de Olavide. Pp. 25-38.

SILVA, Renán. 2005. La Ilustración en el virreinato de Nueva Granada: estudios de historia cultural. Medellín, Colombia: Carreta Editores.

URZAINQUI, Inmaculada (2003). "Un nuevo sistema de escritura y de lectura: la prensa periódica" en Historia de la edición y de la lectura en España, 1472-1914, Biblioteca del libro. Madrid: Fundación Germán Sánchez Ruipérez. Pp. 378-389. 
URZAINQUI, Inmaculada (2007). Hacia una tipología de la traducción en el siglo XVIII: los horizontes del traductor. Alicante: Biblioteca Virtual Miguel de Cervantes. Disponible en: http://www.cervantesvirtual.com/obra/hacia-una-tipologa-de-latraduccin-en-el-siglo-xviii--los-horizontes-del-traductor-0/

URZAINQUI, Inmaculada (2009). «Periodista- espectador en la España de las Luces. La conciencia de un género nuevo de escritura periodística». El Argonauta español. Revue bilingue, franco-espagnole, d'histoire moderne et contemporaine consacrée à l'étude de la presse espagnole de ses origines à nos jours (XVIle-XXIe siècles), 6. DOI: 10.4000/argonauta.516.

USOZ, J. (2013): Los prólogos económicos y la esfera pública ilustrada en España. En J. Astigarraga \& J. Usoz (Eds.), L'Économie politique et la sphère publique dans le débat des Lumières. Madrid: Casa de Velázquez.

VALDEZ GARZA, D. (2014): Libros y lectores en la Gazeta de literatura de México (17881795) de José Antonio Alzate (Primera edición). Madrid: Iberoamericana.

WEINBERG, F. (1956): Estudio preliminar. Vieytes y la revolución-Vieytes y el drama de la agricultura colonial. En J. H. Vieytes, Antecedentes económicos de la revolución de mayo. Buenos Aires: Raigal.

WRIGHT, I. S., \& NEKHOM, L. M. (1994): Diccionario histórico argentino. Buenos Aires: Emecé.

ZINNY, A. (1869): Efemeridografia argirometropolitana hasta la caida del gobierno de Rosas. Buenos Aires: Imprenta del Plata. 